\title{
Studies of Platelet 5-Hydroxytryptamine (Serotonin) in Storage Pool Disease and Albinism
}

\author{
Harvey J. Weiss, Thomas B. Tschopp, John Rogers, and \\ HARVEY BRAND \\ From the Division of Hematology (Department of Medicine), The Roosevelt \\ Hospital and the Columbia University College of Physicians and Surgeons, \\ New York 10019
}

A B S T R A C T Platelets in patients with storage pool disease are markedly deficient in a nonmetabolic (storage) pool of ADP that is important in platelet aggregation. They are also deficient in ATP, although to a lesser degree. In seven patients with this disorder, including one with albinism, platelet 5-hydroxytryptamine (5-HT) levels were reduced in proportion to the reduction in ATP $(r=0.94)$. Their platelets show diminished capacity to absorb $\left[{ }^{14} \mathrm{C}\right] 5-\mathrm{HT}$, and the type of defect was similar to that produced in normal platelets by reserpine, a drug known to inhibit the uptake of 5-HT by the platelet dense granules. Storage pool-deficient platelets also converted more $\left[{ }^{3} \mathrm{H}\right] 5-\mathrm{HT}$ to $\left[{ }^{3} \mathrm{H}\right] 5$-hydroxyindoleacetic acid than did normal platelets, and the platelets in one of two patients studied contained increased amounts of 5-HT metabolites. The above findings, together with those reported previously, support the conclusion that the capacity of the dense granules (which may be either diminished or functionally abnormal) for storing 5-HT is decreased in storage pool disease; as a result, the 5 -HT that enters the platelet may be more exposed to monoamine oxidases present on mitochondrial membranes. This diminished storage capacity (for 5-HT) may also explain why preincubating platelet-rich plasma with 5 -HT for $45 \mathrm{~min}$ without stirring inhibits subsequent platelet aggregation by $5-\mathrm{HT}$ to a greater degree in patients with storage pool disease than in normal subjects. The latter finding is also consistent with the theory that the aggregation of platelets by $5-\mathrm{HT}$ is mediated by the same receptors on the plasma membrane that are involved in its uptake. The diminished release of platelet-bound $\left[{ }^{14} \mathrm{C}\right] 5-\mathrm{HT}$ by collagen that we found in these patients, as well as findings in previous studies, suggests that the release reaction may also be abnormal in storage pool disease.

Received for publication 22 January 1974 and in revised form 8 April 1974.

\section{INTRODUCTION}

The 5-hydroxytryptamine (5-HT, serotonin $)^{1}$ present in blood is found in the platelets (1) and originates from enterochromaffin cells, particularly those in the gastrointestinal tract (2). The transfer of 5-HT from plasma to platelets can occur at a considerable concentration gradient (3), and at least two subcellular sites have been implicated in this transport mechanism. There is evidence that active transport of 5-HT through the platelet membrane (4) may be mediated by specific receptors that appear to be of the classical D-type (5). Within the platelets, $5-\mathrm{HT}$ is stored in granules of high electron density (dense bodies) (6-9), and it has been suggested that the localization of 5-HT within these granules may protect it from the action of metabolizing enzymes (10). In particular, platelets contain monoamine oxidase (11), (presumably located on the external membrane of mitochondria), and the formation of the principal metabolites of 5-HT, 5-hydroxytryptophol and 5-hydroxyindoleacetic acid (5-HIAA) $(10,11)$, is considerably enhanced if the platelets are treated with reserpine, a drug that liberates $5-\mathrm{HT}$ from its storage organelles (10-13). Platelets are also aggregated by 5-HT (14), and recent studies by Baumgartner and Born suggest that 5 -HT-induced platelet aggregation is mediated by the same receptors responsible for its uptake at the plasma membrane (15-17).

The platelet dense granules that store 5-HT also contain appreciable amounts of bivalent cations (18), as well as a special metabolically inactive pool of adenine nucleotides (the storage pool) that is important in platelet aggregation (19-20). We have previously reported a group of patients with a congenital disorder of hemostasis in whom the contents of the platelet dense granules

\footnotetext{
${ }^{1}$ Abbreviations used in this paper: 5-HIAA, 5-hydroxyinoleacetic acid; 5-HT, 5-hydroxytryptamine; PPP, platelet-poor plasma; PRP, platelet-rich plasma; TLC, thinlayer chromatography; $\mathrm{V}$, velocity.
} 
are diminished (21-23). As a result of the diminished amounts of ADP in the storage pool, collagen-induced platelet aggregation is impaired, and the second phase of epinephrine and ADP-induced aggregation is either absent or diminished (24-27). In addition, the release mechanism may also be abnormal in these patients (28). The type of congenital defect present in the platelets of these patients with "storage pool disease" makes them uniquely suitable for studying certain aspects of 5-HT uptake, metabolism, and release, and 5-HT-induced aggregation.

\section{METHODS}

\section{Patients}

The study included six patients with storage pool disease. Three patients (E. P., L. G., and S. N.) are unrelated, while three others (D. C., S. C., and R. C.) are members of a previously described family (family C) (25). In previous studies, all patients showed diminished collageninduced platelet aggregation and absent or diminished second-phase aggregation with epinephrine or ADP (24-27). In addition, the amounts of storage pool ADP and ATP in their platelets were diminished $(21,22)$. Platelet $5-\mathrm{HT}$ levels were decreased in three patients (L. G., D. C., and S. N.), and normal in one patient (E. P.) (22). The levels were not measured in patients $R$. C. and S. C. In the latter study, the normal levels of platelet $5-\mathrm{HT}$ were 126 $\pm 31.6 \mathrm{nmol} / 10^{11}$ platelets. A unique phospholipid abnormality, consisting of an increased lecithin:phosphatidyl ethanolamine ratio, was also found in family $\mathrm{C}$ but not in the other unrelated patients (29). Through the courtesy of Dr. James A. Wolff, we also studied a 10-yr-old girl (S. M.) of Puerto Rican descent with oculocutaneous albinism (30), on whom some of the findings at age 2 have been previously reported (31). She has light blonde hair, and the color of her skin is considerably lighter than that of her parents or siblings. Her irises are blue-grey, and continuous coarse nystagmus was prominent. She has continued to show easy bruising, frequent epistaxis, and excess bleeding after tooth extractions. Our studies showed a platelet count of $233,000 / \mathrm{mm}^{8}$, absent second wave of aggregation with $5 \mu \mathrm{M}$ epinephrine, markedly diminished collageninduced aggregation ( $4 \%$, compared with normal [ $\pm 2 \mathrm{SD}$ ] values of $73 \pm 16 \%$ obtained with a dilute suspension of collagen $[25,26])$, and disaggregation, after normal initial aggregation, with $4 \mu \mathrm{M}$ ADP.

Control subjects were normal hospital employees. Both control subjects and patients took no drugs for at least $1 \mathrm{wk}$ before the study.

\section{Blood}

Venous blood was mixed with $3.2 \%(0.108 \mathrm{M})$ sodium citrate $(9: 1)$ and centrifuged at $1,500 \mathrm{~g}$ and $20^{\circ} \mathrm{C}$ for 3 min to obtain platelet-rich plasma (PRP). To obtain platelet-poor plasma (PPP), the blood was centrifuged at $2,400 \mathrm{~g}$ for $30 \mathrm{~min}$ at $4^{\circ} \mathrm{C}$. All glassware was siliconecoated (SC-87 Dri-Film, General Electric, Schenectady, N. Y. $15 \%$ in toluene).

\section{Platelet aggregation}

$2 \mathrm{ml}$ of PRP were stirred at $37^{\circ} \mathrm{C}$ in the cuvette of a Payton dual-channel aggregation module (Payton Asso- ciates, Buffalo, N. Y.), and platelet aggregation was recorded continuously as the increase in light transmittance (relative to a PPP blank) on a Riken-Denshi (Tokyo, Japan) recorder with a chart speed of $30 \mathrm{~mm} / \mathrm{min}$. We determined the maximum slope of the aggregation curve by drawing a tangent to the curve at the point of inflection, and the velocity of aggregation in $\mathrm{mm} / \mathrm{min}$ was calculated as the (slope) $\times$ (chart speed).

\section{Determination of ATP and ADP in platelets}

PRP was mixed in an ice bath for $10 \mathrm{~min}$ with an equal volume of $96 \%$ ethanol containing $10 \mathrm{mM}$ EDTA. After centrifugation at $4^{\circ} \mathrm{C}$ and $14,000 \mathrm{~g}$ for $20 \mathrm{~min}$, the ethanol extracts were stored at $-60^{\circ} \mathrm{C}$. Determination of ADP and ATP in the extracts was by the method of firefly luminescence $(22,32)$ with dessicated firefly lantern extracts (Fle-50, Sigma Chemical Co., St. Louis, Mo.) as the source of the luciferase. The reaction was carried out in a dark cell, and the light flash was measured with a photometer coupled to an Aminco-Bowman photomultiplier microphotometer (American Instrument Co., Inc., Silver Spring, Md.) and recorded on a 10-in strip chart potentiometric recorder (Beckman Instruments, Inc., Fullerton, Calif.).

\section{Measurement of 5-HT in platelets}

The method used was a modification of the method of Crosti and Luchelli $(33,34)$ as previously described, (22), except that in the present study fluorescence was measured in an Aminco-Bowman spectrofluorometer with excitation at $295 \mathrm{~nm}$ and emission at $540 \mathrm{~nm}$, whereas in the previous study the instrument was a Farrand Ratio Fluorometer with a $295 \mathrm{~nm}$ interference filter for excitation light (Farrand Optical Co., Inc., Valhalla, N. Y.) and a Corning filter (3-69, Corning Glass Works, Science Products Div., Corning, N. Y.) for the fluoresced light. Since the fluorescence properties of all 5-hydroxyindoles are similer at $\mathrm{pH}$ values below 2 (2), the values obtained by this method are not specific for 5-HT.

\section{5-HT uptake}

[side chain-2- $\left.{ }^{14} \mathrm{C}\right] 5-\mathrm{HT}$ creatinine sulfate $(57 \mathrm{mCi} / \mathrm{mmol}$, Amersham/Searle Corp., Arlington Heights, I11.), dissolved in $70 \%$ ethanol to a concentration of $2 \mathrm{mM}$, was stored at $-20^{\circ} \mathrm{C} .10 \mu \mathrm{l}$ of this solution of radioactive $5-\mathrm{HT}$ were added to $10 \mathrm{ml}$ of PRP (adjusted to a platelet count of $200,000 / \mathrm{mm}^{3}$ with autologous PPP), to give a final $5-\mathrm{HT}$ concentration of $2 \mu \mathrm{M}$. The mixture was incubated in a plastic tube at $37^{\circ} \mathrm{C}$, and at intervals of $1,3,5,10,30$, and $60 \mathrm{~min}, 1-\mathrm{ml}$ samples were removed and immediately placed in melting ice. At the end of $60 \mathrm{~min}$, all specimens were centrifuged together at $10,000 \mathrm{~g}$ and $4^{\circ} \mathrm{C}$ for $30 \mathrm{~min}$ in a Sorvall RC2-B centrifuge (Ivan Sorvall, Newtown, Conn.). The supernate was removed, and the radioactivity in $100 \mu 1$ was determined in a liquid scintillation vial containing $15 \mathrm{ml}$ of Bray's solution, with a Tri-Carb dual-channel liquid scintillation counter (Packard Instrument Co., Inc., Downers Grove, I11.). The amount of radioactivity remaining in the supernatant plasma was compared with the total radioactivity added (the latter determined from a sample of the incubation mixture in which the platelets had been lysed by the addition of $1 / 20$ vol of $20 \%$ Triton X-100, Rohm and Haas Co., Philadelphia), and results were expressed as the percent activity taken up by the platelets. In most studies, we also measured the radioactivity in the 
platelet pellet directly. This was done by resuspending the pellet in $1 \mathrm{ml}$ of PPP containing $1 \%$ Triton X-100 and counting the radioactivity as described above. When measured in this way, the calculated percent uptake of radioactive 5-HT into platelets was generally $1-5 \%$ lower than when calculated by the first method, in which it was assumed that all of the loss of radioactivity from the plasma could be accounted for by uptake into the platelets. This was observed in both normal subjects and in patients.

\section{Collagen-induced release of platelet-bound $\left[{ }^{14} \mathrm{C}\right] 5-\mathrm{HT}$}

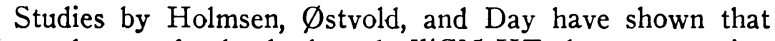
the release of platelet-bound $\left[{ }^{14} \mathrm{C}\right] 5-\mathrm{HT}$ by aggregating agents parallels that of endogenous $5-\mathrm{HT}$ and therefore can be used to assess the platelet release reaction (35). In this study, we used a suspension of human connective tissue, undiluted or diluted $1: 2$ in saline and prepared as previously described (36), as a source of collagen. Platelets were labeled with radioactive 5-HT by incubating PRP with 2 $\mu \mathrm{M}\left[{ }^{14} \mathrm{C}\right] 5-\mathrm{HT}$ for $30 \mathrm{~min}$, and the percent of the radioactivity incorporated into platelets was determined on a sample as described above. Two ather 2-ml samples were stirred with $0.1 \mathrm{ml}$ of either undiluted or diluted collagen in the aggregation module for $6 \mathrm{~min}$ and then centrifuged immediately for $10 \mathrm{~min}$ in a Clay-Adams serofuge (ClayAdams, Inc., Parsipanny, N. J.). The supernate was removed, and the percent of the platelet-bound $\left[{ }^{14} \mathrm{C}\right] 5-\mathrm{HT}$ released by collagen was determined.

\section{Metabolism of platelet-bound radioactive 5-HT}

Incubation of PRP with radioactive 5-HT and preparation of extracts for chromatography. Citrated PRP, adjusted to a platelet count of $200,000 / \mathrm{mm}^{3}$ with autologous $\mathrm{PPP}$, and containing less than $500 \mathrm{red}$ blood cells $/ \mathrm{mm}^{3}$, was incubated at $37^{\circ} \mathrm{C}$ for $5 \mathrm{~h}$ with $5 \mu \mathrm{M}\left[{ }^{3} \mathrm{H}\right] 5-\mathrm{HT}$. Studies on patient E. P. and a control subject studied on the same day were performed with $\left[\mathrm{G}-{ }^{3} \mathrm{H}\right] 5-\mathrm{HT}$ creatinine sulfate $(6.8 \mathrm{Ci} / \mathrm{mol}$, Amersham/Searle Corp.) and on all other patients (and controls run the same day) [side chain-1,2- ${ }^{3} \mathrm{H}$ $(N)$ ]5-HT binoxalate $(1.3 \mathrm{Ci} / \mathrm{mmol}$, New England $\mathrm{Nu}-$ clear, Boston, Mass.). (These two chemical forms of $\left[{ }^{3} \mathrm{H}\right]-$ 5 -HT could be used interchangeably, as indicated by the virtually identical results obtained in parallel studies on control subjects). The $\mathrm{pH}$ at the end of the incubation period was $8.18 \pm 0.04$ for all specimens. After incubation, $4 \mathrm{ml} \mathrm{PRP}$ was centrifuged at $12,000 \mathrm{~g}$ and $4^{\circ} \mathrm{C}$ for $10 \mathrm{~min}$. The platelet pellet and $2 \mathrm{ml}$ of the supernatant plasma were extracted with $2 \mathrm{ml}$ and $1 \mathrm{ml}$ of $1 \mathrm{M} \mathrm{HClO}_{4}$, respectively, for $10 \mathrm{~min}$ at $4^{\circ} \mathrm{C}$, and the protein precipitates were sedimented by centrifugation at $20,200 \mathrm{~g}$ for $5 \mathrm{~min} .1 .5 \mathrm{ml}$ of each supernate was then treated with either $1.5 \mathrm{ml}$ (pellet supernate) or $0.5 \mathrm{ml}$ (plasma supernate) of $0.6 \mathrm{M}$ $\mathrm{K}_{2} \mathrm{CO}_{3}$ to bring the $\mathrm{pH}$ to 7.4 and to remove $\mathrm{ClO}_{4}^{-}$. The $\mathrm{KClO}_{4}$ was sedimented by high speed centrifugation for 5 min, and the neutralized extracts were mixed $(1: 1)$ with a standard solution (37) that contained 5-HT (Sigma), 5HIAA (Sigma), and 5-hydroxytryptophol, (Regis Chemical Co., Morton Grove, Ill.) in concentrations of $1 \mathrm{mM}$. The extract-standard mixtures were stored at $-60^{\circ} \mathrm{C}$.

Paper chromatography. The above extracts were thawed, $20-\mu 1$ aliquots were spotted under nitrogen on Whatman no. 1 chromatography paper $(1 \times 10$-in strips $)$ and the indoles were separated by ascending chromatography for $6 \mathrm{~h}$ in the dark with isopropanol: $\mathrm{H}_{2} \mathrm{O}$ : concentrated am-

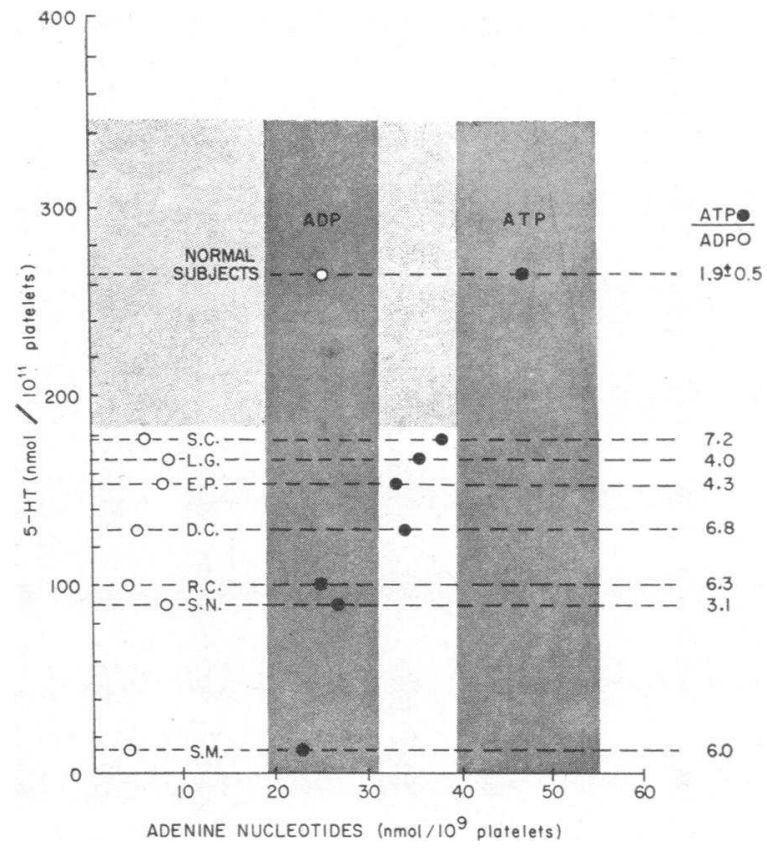

FIGURE 1 5-HT and adenine nucleotide content of platelets. Along each dashed line (the level of the 5-HT value) is shown the values obtained for ADP (O), ATP (•) and the ATP/ADP ratio in 13 normal subjects (mean values $\pm 2 \mathrm{SD}$ ) and 7 patients with storage-pool disease (S. M. is the patient with albinism). Normal values ( $\pm 2 \mathrm{SD})$ are enclosed in the light stippled (5-HT) and heavy stippled (adenine nucleotide) areas. The equation of the least squares regression line for the relationship between 5-HT and ATP is : $y=9.5-181 x(r=0.94)$.

monia (20:2:1) solvent (38). The strips were dried and sprayed with $\mathrm{HCl} /$ methanol for visualization of the spots under ultraviolet light. They were then cut into six zones, and the radioactivity was eluted with $4 \mathrm{ml}$ of methanol, twice, followed by $4 \mathrm{ml}$ of acetone, twice. The combined elutants from each zone were evaporated overnight at $70^{\circ} \mathrm{C}$ in counting vials, and radioactivity was determined in the Tri-Carb scintillation counter after addition of $11 \mathrm{ml}$ of Bray's solution to each vial. Counting efficiency was $8-15 \%$. Recovery of radioactivity in the neutralized extracts was 60 $80 \%$ and from the extracts after chromatography and elution was $95-100 \%$. Results, expressed as picomoles of radioactive 5-HT or metabolites per milliliter of PRP, were calculated from the counts per minute, corrected for counting efficiency, extraction recovery, and dilutions. The radioactivity in the zone that contained the 5-HIAA (zone 2) were doubled to account for the $50 \%$ loss of specific activity that occurs in the conversion of $\left[{ }^{3} \mathrm{H}\right] 5-\mathrm{HT}$ binoxalate to $\left[{ }^{3} \mathrm{H}\right] 5$-HIAA.

\section{Detection of endogenous 5-HT metabolites in platelets}

Extraction of platelets. Citrated PRP was centrifuged at $12,000 \mathrm{~g}$ and $4^{\circ} \mathrm{C}$ for $10 \mathrm{~min}$, and the platelet pellet was

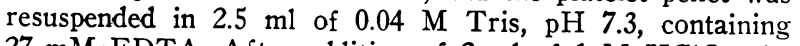
$27 \mathrm{mM}$ EDTA. After addition of $2 \mathrm{ml}$ of $1 \mathrm{M} \mathrm{HClO}_{4}$, the protein precipitate was removed by centrifugation, and the 
5-HT metabolites (5-HIAA and 5-hydroxytryptophol) in the acidic supernate were extracted with $4 \mathrm{ml}$ of ethyl acetate. Under these conditions, Bartholini, Pletscher, and Bruderer (12) showed, using thin layer chromatography (TLC), that 5-HT remains in the aqueous phase while 5HIAA and 5-hydroxytryptophol are found in the organic phase, and we confirmed this observation. After evaporation of the ethyl acetate at $37^{\circ} \mathrm{C}$ under a flow of $\mathrm{N}_{2}$, the $5-\mathrm{HT}$ metabolites were dissolved in $100 \mu \mathrm{l}$ of methanol.

TLC. $50 \mu \mathrm{l}$ of the methanol extracts were spotted under $\mathrm{N}_{2}$ on a silica gel TLC plate. The extracts were chromatographed, together with similar volumes containing 5-HIAA and 5-hydroxytryptophol standards, for $2 \frac{1}{2} \mathrm{~h}$ with isopropanol: methyl acetate: $\mathrm{H}_{2} \mathrm{O}$ : concentrated $\mathrm{NH}_{3}$ (35:45: $2: 18)$ as solvent. The plates were sprayed with $\mathrm{HCl}$ \% methanol, and fluorescence of the spots was developed by exposure to ultraviolet light. This method could detect 2-3 nmol of 5-HIAA or 5-hydroxytryptophol.

Quantitative determination of 5-hydroxyindoles in extracts. 5-hydroxyindoles in the aqueous phase, containing 5 -HT, and organic phase, containing 5-HIAA and 5-hydroxytryptophol, obtained after extraction of the acidic supernates into ethyl acetate (see above) were determined in $3 \mathrm{~N} \mathrm{HCl}$ by the spectrofluorometric method described in a previous section. The amount of metabolite was expressed as the percent of the total 5-hydroxyindoles.

\section{Drugs}

Reserpine phosphate and imipramine $\mathrm{HCl}$ were obtained from the CIBA Pharmaceutical Company, Div. of the CibaGeigy Corporation (Summit, N. J.) and were dissolved in water for in vitro studies. 5-HT creatinine sulfate was purchased from the Sigma Chemical Co., and was dissolved in $0.9 \% \mathrm{NaCl}$. Epinephrine $\mathrm{HCl}$ (Parke, Davis \& Company, Detroit, Mich.) was also dissolved in saline.

\section{Statistical methods}

$\mathrm{SD}, \mathrm{SE}$, and equations for the regression line between two variables were determined by standard methods (39).

\section{RESULTS}

5-HT and adenine nucleotide content of platelets. Results are shown in Fig. 1. In normal subjects, the values obtained for $5-\mathrm{HT}$ were $265 \pm 40$ (SD) nmol $/ 10^{11}$ platelets. The values obtained in this study, in which a spectrofluorometer was used to measure fluorescence, were approximately twice those obtained in a previous study in which fluorescence was determined by a filter fluorometer. The reason for this discrepancy is not known, but

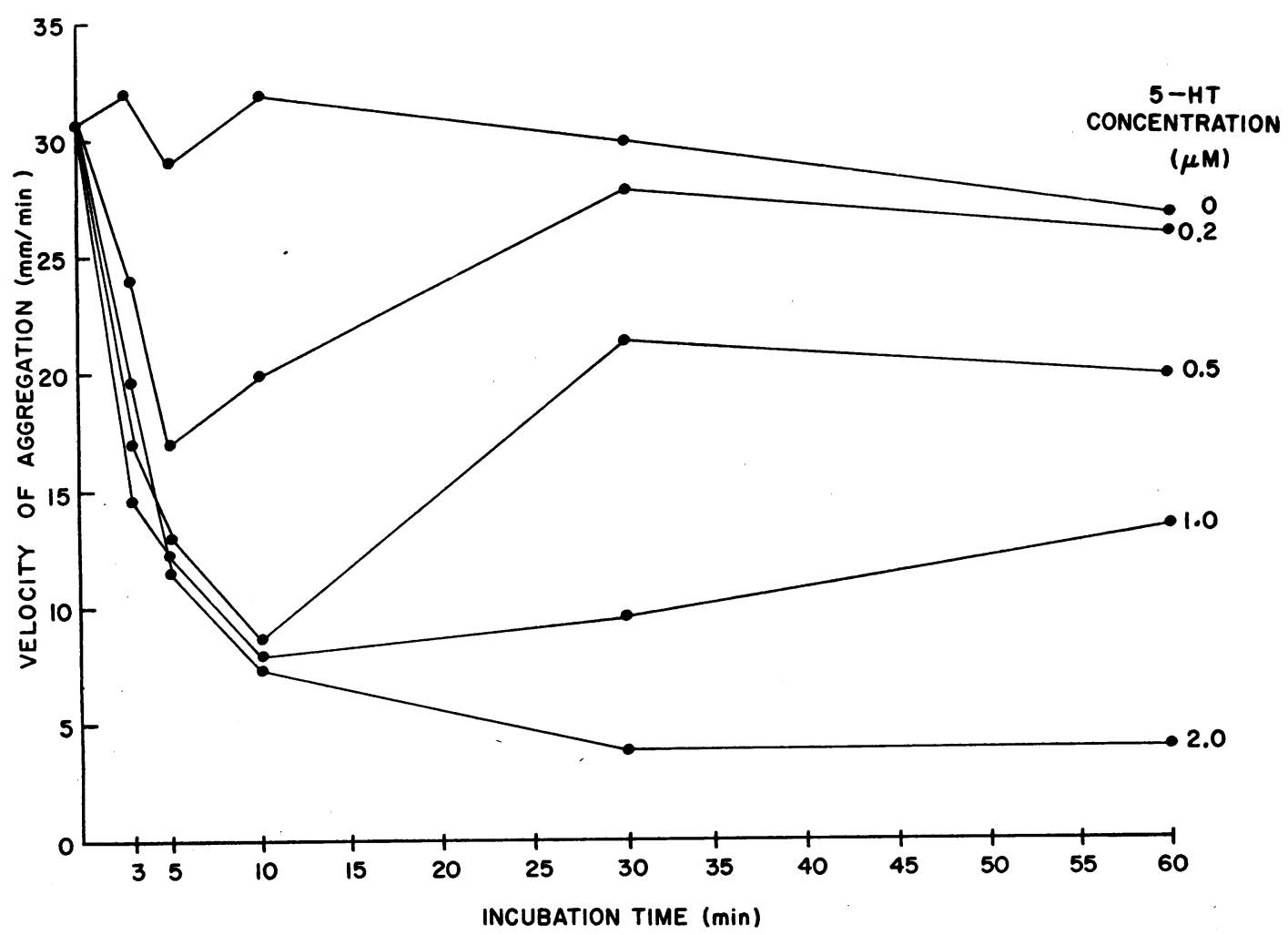

FIGURE 2 Effect of preincubating normal PRP with different concentrations of 5-HT for varying periods of time on the subsequent platelet aggregation by $5-\mathrm{HT}$ (epinephrine). Citrated PRP from a normal subject was incubated at $37^{\circ} \mathrm{C}$ (without stirring) with $1 / 20$ vol of 5-HT in the final concentrations indicated. Samples were transferred to the aggregometer cuvettes at the time indicated and $1 / 20$ vol of a solution containing 5-HT and epinephrine (final concentrations of $5 \mu \mathrm{M}$ and $1 \mu \mathrm{M}$, respectively) was added to the stirred PRP. The velocity of aggregation was determined as described in Methods. 


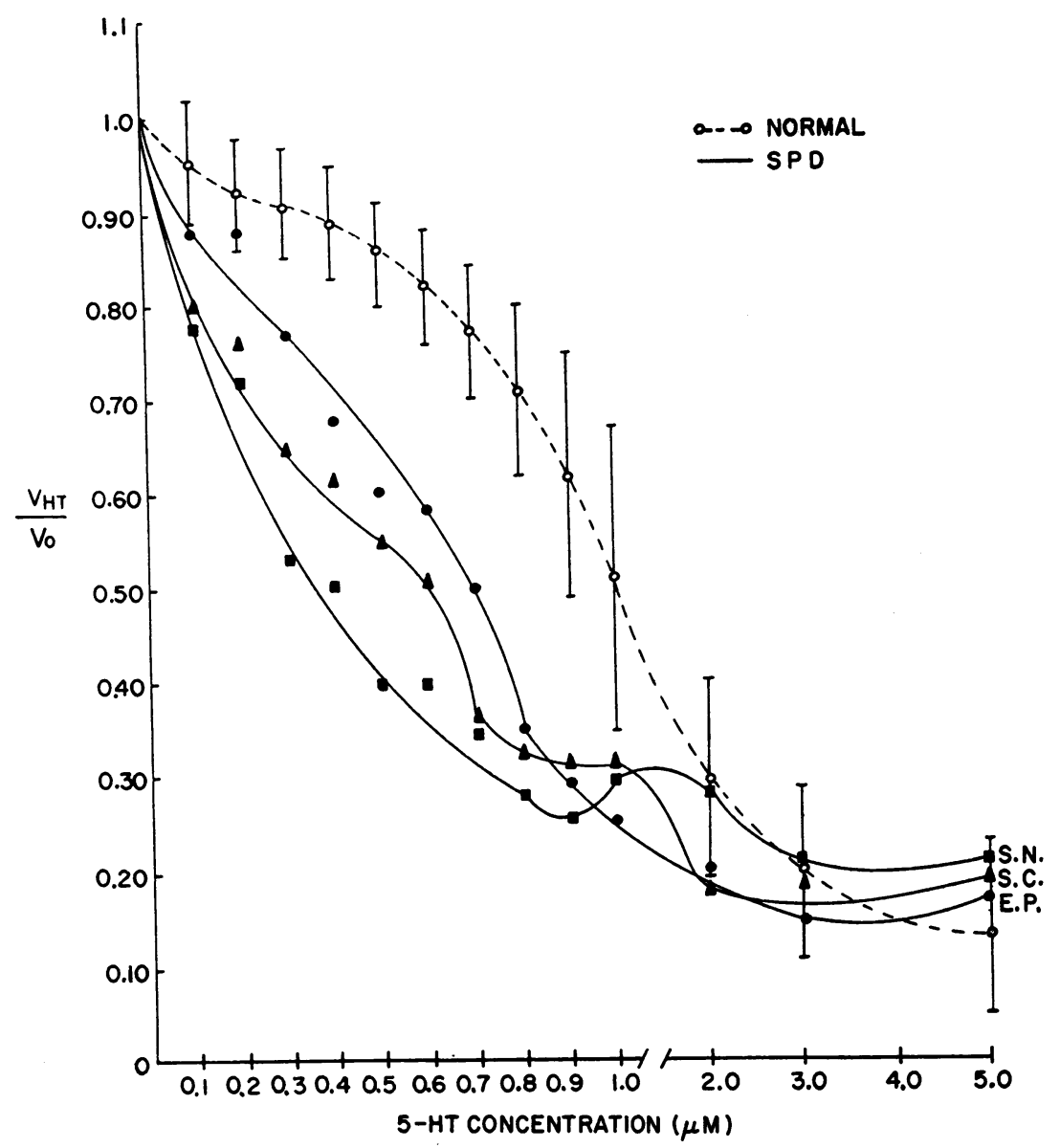

FIGURE 3 Effect of preincubating PRP for $45 \mathrm{~min}$ with varying concentrations of 5-HT on subsequent platelet aggregation by 5-HT (epinephrine). Conditions were similar to those in Fig. 2. Results are expressed as the ratio of the velocity of aggregation obtained after preincubation with 5-HT ( $\left.\mathrm{V}_{\mathbf{H T}}\right)$ to the velocity obtained on the same PRP incubated with saline $\left(\mathrm{V}_{0}=0\right.$ concentration of $\left.5-\mathrm{HT}\right)$. The inhibitory effects of preincubating the PRP with 5-HT are more pronounced in patients S. N., S. C., and E. P. with storage pool disease (SPD) than in normal subjects, whose mean $\pm \mathrm{SD}$ values are connected by the dashed line.

exactly the same findings have been reported recently by Holmsen et al. (35). The amount of 5-HT in the platelets of patients with storage-pool disease was decreased in all cases. The most striking defect was obtained in the patient (S. M.) with albinism, whose platelets contained only $13 \mathrm{nmol} / 10^{11}$ cells ( $5 \%$ of the normal value). In patients S. N., R. C., and D. C., the values of 90,100 , and $125 \mathrm{nmol}$ were $34-47 \%$ of the mean value obtained in normal subjects. The values of 180,167 , and 155 nmol, obtained in patients S. C., L. G., and $E$. P., represented only modest reductions in the 5-HT content of their platelets. The decreased content of platelet ADP (and to a somewhat lesser extent of ATP) and the increase in the ATP/ADP ratio previously described for patients with storage pool disease $(21,22)$ were again obtained. Similar findings were also obtained in the patient (S. M.) with albinism.
There was a good correlation $(r=0.94)$ between the amounts of 5-HT and ATP in the platelets (Fig. 1).

Aggregation of platelets by 5-HT and by a mixture of 5-HT and epinephrine. As reported by others $(14,15)$, we found that 5 -HT produces weak aggregation of human platelets, consisting of a single, reversible wave. However, the aggregation of platelets by $5-\mathrm{HT}$ is markedly increased by the simultaneous addition of epinephrine in concentrations that, by themselves, produce only a small first wave $(15,16)$. We therefore used a mixture of 5-HT (final concentration $5 \mu \mathrm{M}$ ) and epinephrine (final concentration $1 \mu \mathrm{M}$ ) to aggregate platelets in this study. The velocity (V) of the first wave of aggregation produced by this mixture of 5-HT and epinephrine will henceforth be referred to as 5-HT (epinephrine)-induced platelet aggregation. We confirmed the findings of Baumgartner and Born that 5-HT (epineph- 
rine)-induced platelet aggregation was diminished by prior incubation without stirring with $5-\mathrm{HT}(15,16)$. This inhibitory effect of 5-HT was dose-dependent and progressive during the first 5-10 $\mathrm{min}$ of incubation (Fig. 2). With continued incubation (except for the highest concentration of $5-\mathrm{HT}$ ), the platelets gradually regained their ability to aggregate with 5 -HT (epinephrine).

We next studied whether the behavior of platelets in storage pool disease was similar to that described above in normal subjects. We incubated PRP with increasing concentrations of 5 -HT $(0.1-5.0 \mu \mathrm{M})$ for $45 \mathrm{~min}$ at $37^{\circ} \mathrm{C}$ and then studied 5-HT (epinephrine)-induced platelet aggregation. The results are shown in Fig. 3 and demonstrate that for each concentration of 5-HT used during the 45-min incubation period, the subsequent aggregation of storage pool platelets by $5-\mathrm{HT}$ (epinephrine) ( $\mathrm{V}_{\text {нт }}$ ) was less, relative to the control value, $\mathrm{V}_{\mathbf{0}}$, than that obtained with normal platelets. The results of these studies indicate that the inhibition of 5-HT (epinephrine)-induced aggregation by prior incubation of the platelets with 5-HT, first described by Baumgartner and Born $(15,16)$, is more apparent in patients with storage pool disease than in normal subjects.

Uptake of radioactive 5-HT into platelets. PRP was incubated with $\left[{ }^{14} \mathrm{C}\right] 5-\mathrm{HT}$, as described in Methods. The uptake of radioactivity into the platelets of normal subjects was rapid during the first 5-10 min, and saturation levels of $95 \pm 2$ (SD)\% uptake were obtained after $30 \mathrm{~min}$ (Fig. 4). In five patients with storage pool disease, the saturation levels (but not the initial rates of uptake) were decreased (Fig. 4). The most pronounced abnormalities were observed with the platelets of patient S. N. and in the patient (S. M.) with albinism.

The shape of the 5-HT uptake curves in patients with storage pool disease were similar to those produced by incubating normal PRP with varying concentrations of reserpine, a drug that inhibits the uptake of 5-HT into the platelet granules (40-42). Reserpine had no effect on the initial rate of uptake, but decreased the saturation levels of $\left[{ }^{14} \mathrm{C}\right] 5-\mathrm{HT}$ (Fig. 5). By contrast, imipramine, a membrane-active drug $(40,43)$, inhibited the initial

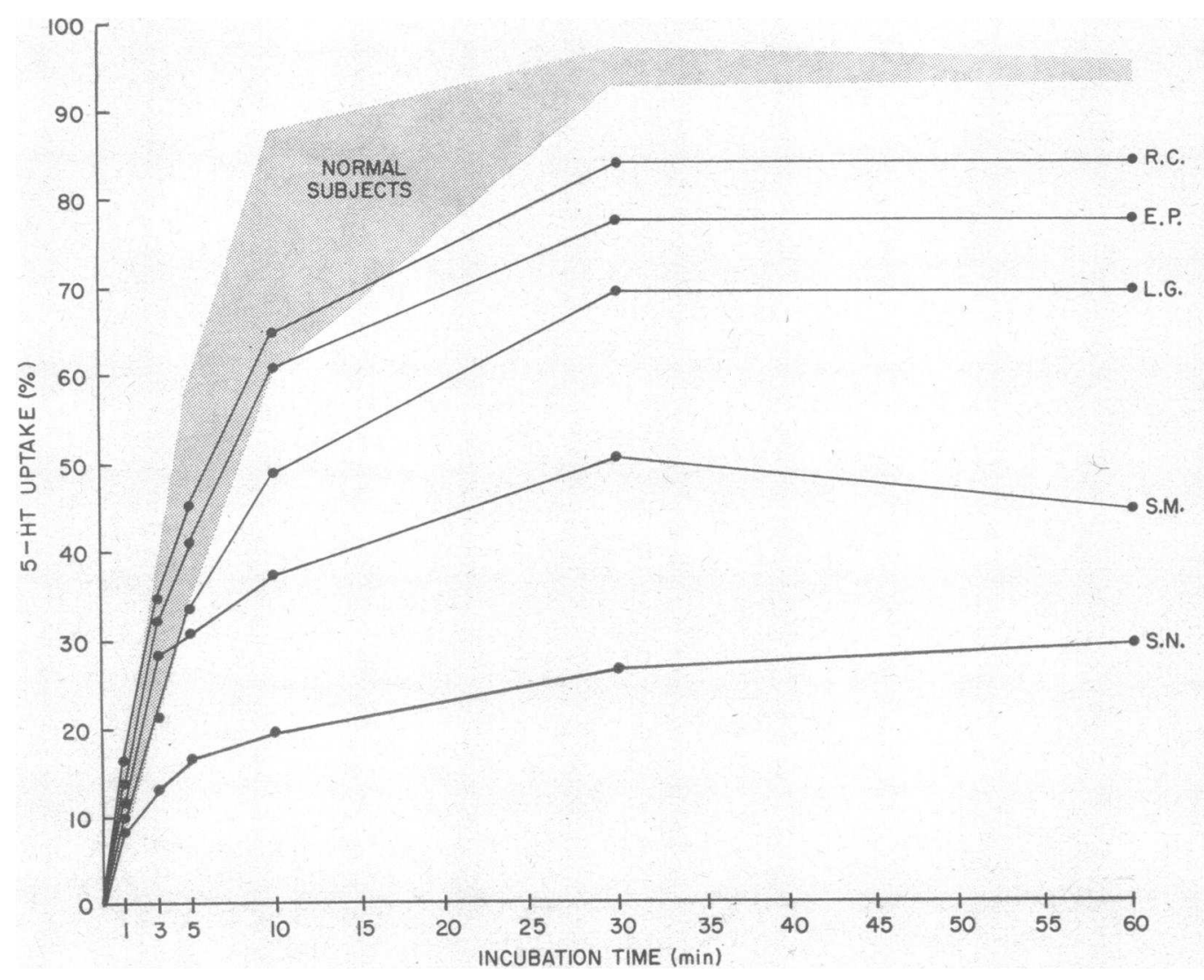

FIGURE 4 Uptake of radioactivity into platelets obtained during incubation of PRP with $\left.{ }^{14} \mathrm{C}\right] 5-\mathrm{HT}$. PRP was incubated at $37^{\circ} \mathrm{C}$ with a $2 \mu \mathrm{M}$ concentration of $\left[{ }^{14} \mathrm{C}\right] 5-\mathrm{HT}$ and the $\left[{ }^{14} \mathrm{C}\right] 5-\mathrm{H}$. The stippled area encloses the mean \pm SD obtained in normal subjects. Closed circles are values obtained in patients with storage pool disease. 


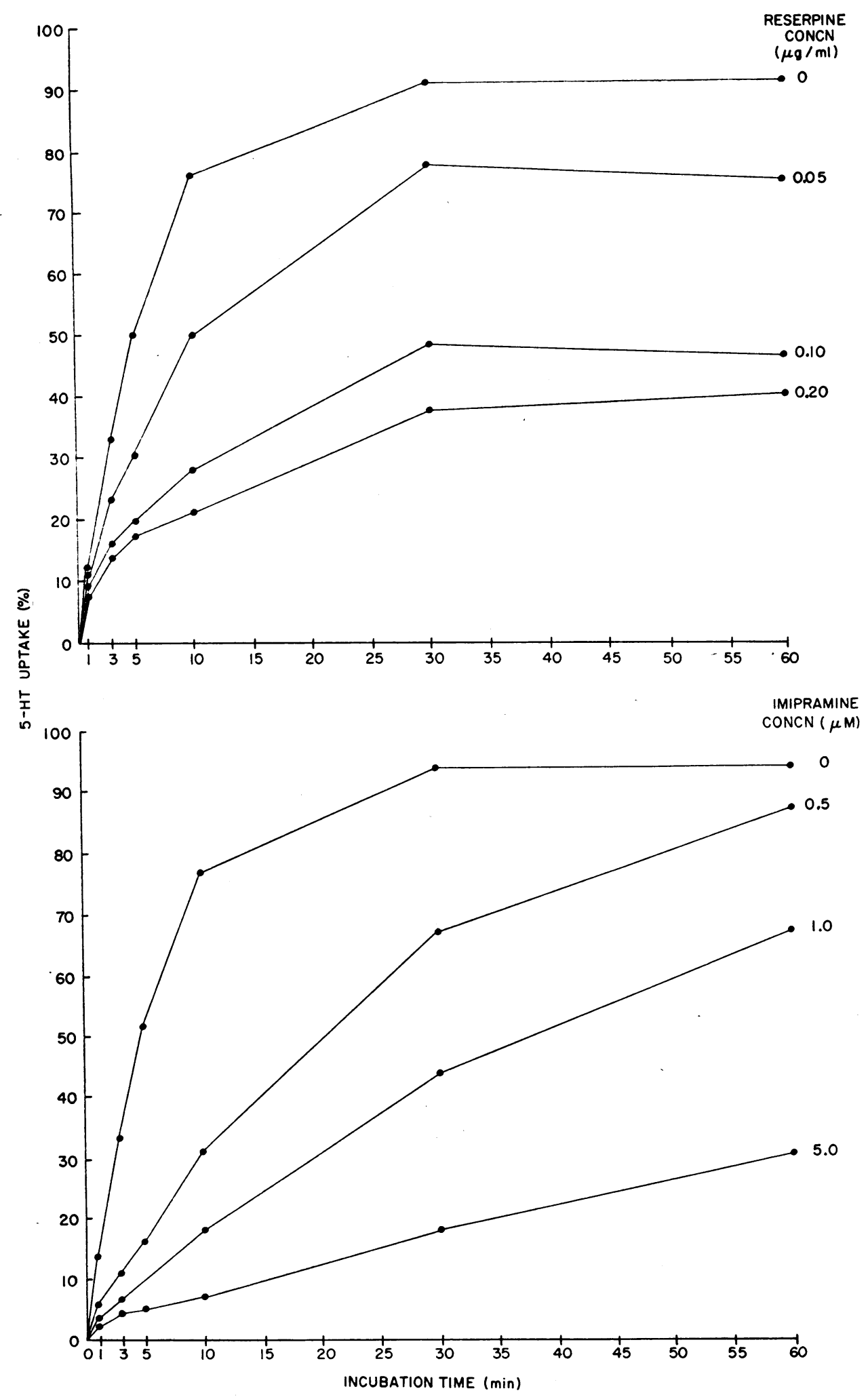

FIGURE 5 Effect of reserpine and imipramine on the uptake of $\left[{ }^{14} \mathrm{C}\right] 5-\mathrm{HT}$ into normal platelets. Experimental conditions were similar to those in Fig. 4 except that PRP contained $1 / 20 \mathrm{vol}$ of reserpine (above) or imipramine (below) in the concentration indicated. 
rate of uptake, but the platelets continued to accumulate 5-HT during the incubation period (Fig. 5).

Release of platelet-bound $\left[{ }^{14} \mathrm{C}\right] 5-H T$. In addition to the impairment of the 5-HT uptake described above, the release of platelet-bound $\left[{ }^{14} \mathrm{C}\right] 5-\mathrm{HT}$ by collagen was also impaired in patients with storage pool disease. This is demonstrated by the findings shown in Fig. 6 . When stirred with PRP from normal subjects, undiluted or diluted collagen released $77 \pm 12$ ( $2 \mathrm{SD}) \%$ or $63 \pm 12$ (2 SD) $\%$ of the platelet-bound $\left[{ }^{14} \mathrm{C}\right] 5-\mathrm{HT}$ into the plasma. Impaired release of $5-\mathrm{HT}$ was obtained in all four patients with storage pool disease studied. The figure also shows, for comparison, the well-known inhibitory effects of aspirin on the platelet release reaction $(36,44)$.

Metabolism of radioactive 5-HT by platelets. PRP was incubated for $5 \mathrm{~h}$ with $\left[{ }^{3} \mathrm{H}\right] 5-\mathrm{HT}$, and the platelets and plasma were separated and analyzed by paper chromatography for 5-HT and its two principal metabolites, 5-HIAA and 5-hydroxytryptophol (see Methods and Fig. 7). Previous studies have shown that radioactive metabolites of 5-HT that are formed in the platelets can pass into the plasma (12). In addition, 5-HT is not metabolized by human plasma $(45,46)$. Therefore, the

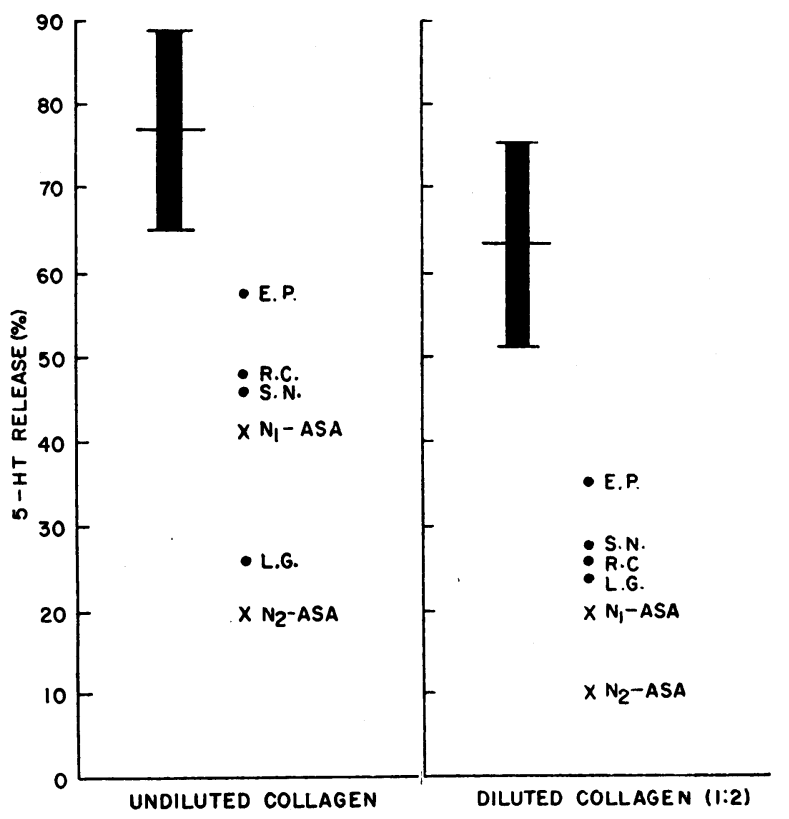

Figure 6 Release of platelet-bound $\left[{ }^{14} \mathrm{C}\right] 5-\mathrm{HT}$. PRP was incubated first for $30 \mathrm{~min}$ at $37^{\circ} \mathrm{C}$ with $2 \mu \mathrm{M}\left[{ }^{14} \mathrm{C}\right] 5-\mathrm{HT}$. A 2-ml sample was then stirred in the aggregation module for $6 \mathrm{~min}$ with $0.1 \mathrm{ml}$ of either undiluted or diluted $(1: 2)$ collagen and the amount of released radioactivity (expressed as a percent of the amount taken up by the platelets) was determined. The solid bars depict the mean \pm SD values obtained in normal subjects. Individual values are those obtained in patients with storage pool disease $(\bullet)$ and in two normal subjects $\left(\mathrm{N}_{1}\right.$ and $\left.\mathrm{N}_{2}\right)$ who had ingested $1.2 \mathrm{~g}$ of aspirin $2 \mathrm{~h}$ before their blood was obtained (X).

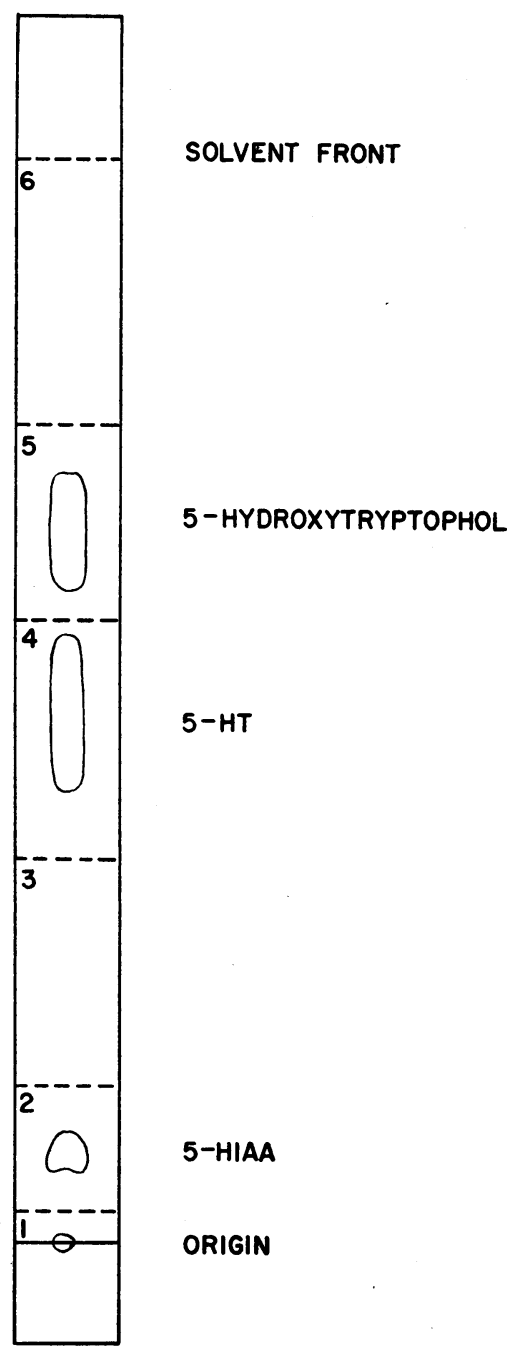

FIGURE 7 Separation of radioactive hydroxyindoles by paper chromatography. Paper chromatography was performed on neutralized platelet and plasma extracts (see section in Methods on radioactive metabolites) obtained after incubation of PRP for $5 \mathrm{~h}$ with $\left[{ }^{3} \mathrm{H}\right] 5-\mathrm{HT}$. The diagram depicts the relative positions of 5-HT, 5-HIAA, and 5-hydroxytryptophol. The strips were cut into six sections along the dashed lines, and the radioactivity in the strips was eluted and counted (see Table I). Radioactivity in zone 3 could be either an unidentified metabolite or trailing from the adjacent 5-HT zone.

ratio of the total amount of ${ }^{3} \mathrm{H}$ metabolites (in platelets and plasma) to that of $\left[{ }^{3} \mathrm{H}\right] 5-\mathrm{HT}$ in the platelets is an indication of the extent to which the $\left[{ }^{3} \mathrm{H}\right] 5-\mathrm{HT}$ in the platelets has been metabolized. The results are shown in Table I. The ratio of ${ }^{8} \mathrm{H}$ metabolites to $\left[{ }^{3} \mathrm{H}\right] 5-\mathrm{HT}$ in normal subjects was $0.44 \pm 0.06$ (SD). Strikingly increased values were obtained in patients E. P. and L. G., and the albino patient S. M. $(2.08,0.78$, and 7.56 , respectively). In all cases, this increase was primarily due to an increased amount of $\left[{ }^{3} \mathrm{H}\right] 5$-HIAA. By con- 
TABLE I

Amount of Radioactive Hydroxyindoles after Incubation of PRP with $\left[{ }^{3} \mathrm{H}\right] 5-\mathrm{HT}$

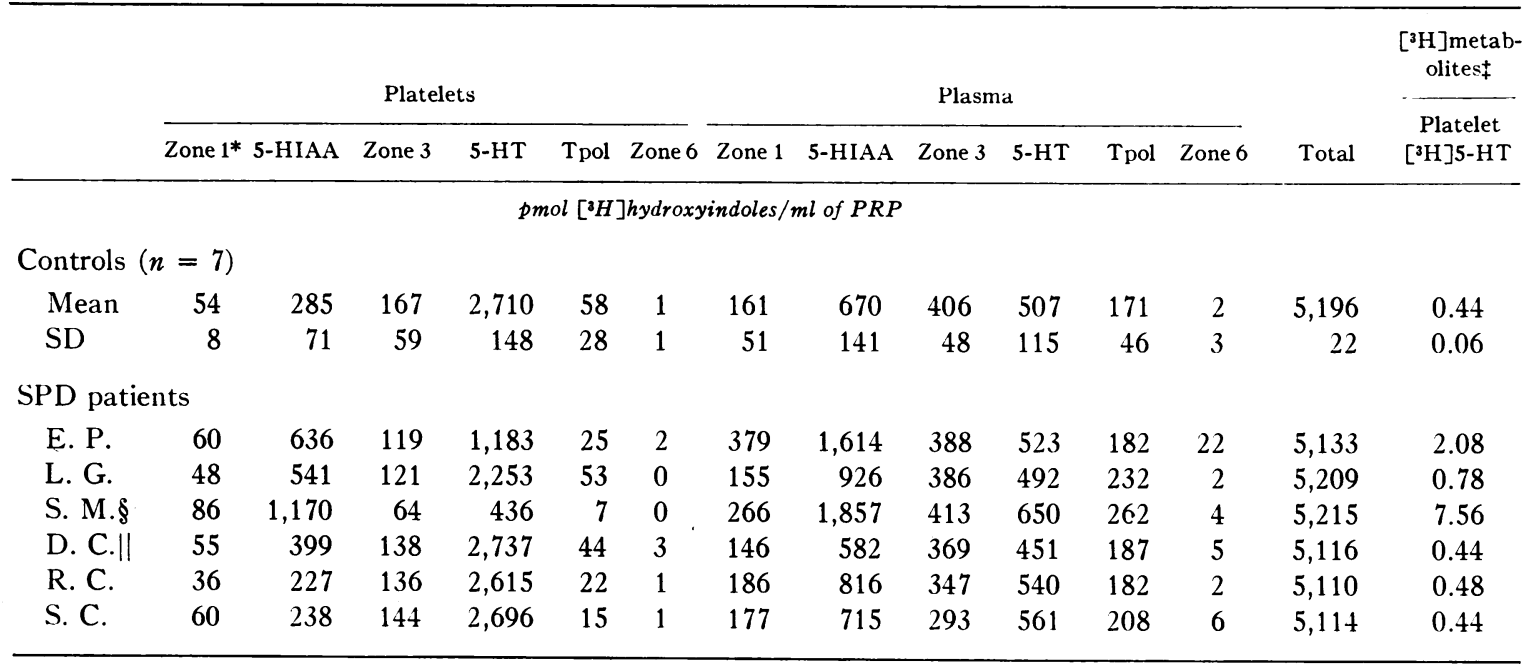

* PRP was incubated with $\left[{ }^{3} \mathrm{H}\right] 5-\mathrm{HT}(5,000 \mathrm{pmol} / \mathrm{ml})$ for $5 \mathrm{~h}$ and 5 -hydroxyindoles were separated by paper chromatography (Fig. 7). The origin is enclosed in chromatogram zone 1 . After chromatography of $\left[{ }^{3} \mathrm{H}\right] 5-\mathrm{HT}$ alone, $95 \%$ of the radioactivity was recovered in the 5-HT zone.

$\ddagger$ Metabolites are the total amounts of $\left[{ }^{3} \mathrm{H}\right] 5$-HIAA and $\left[{ }^{3} \mathrm{H}\right] 5$-hydroxytryptophol (Tpol) in platelets and plasma.

$\S \mathrm{S}$. M. is a patient with oculocutaneous albinism.

II D. C., R. C., and S. C. are members of family C.

trast, radioactive metabolites were not increased in any of the three members of family $\mathrm{C}$.

Content of endogcnous 5-HT metabolites in platelcts. The above studies indicated that the platelets of some patients with storage pool disease could metabolize $\left[{ }^{3} \mathrm{H}\right]-$ 5 -HT more rapidly than normal platelets. This suggested

TABLE II

Endogenous Metabolites (5-HIAA + 5-Hydroxytryptophol) in Platelets

\begin{tabular}{|c|c|c|c|c|c|}
\hline & \multirow[b]{2}{*}{ PRP } & \multirow{2}{*}{$\begin{array}{c}\text { No. of } \\
\text { platelets } \\
\text { extracted } \\
\left(\times 10^{-11}\right)\end{array}$} & \multicolumn{2}{|c|}{ 5-Hydroxyindole content* } & \multirow[b]{2}{*}{$\%$ Metabolites } \\
\hline & & & $5-\mathrm{HT}$ & 5-HIAA + Tpol & \\
\hline \multicolumn{3}{|c|}{$m l$} & \multicolumn{2}{|c|}{ nmol/1011 platelets } & $\%$ total indoles \\
\hline \multicolumn{6}{|c|}{ Control subjects } \\
\hline D. Y. & 66 & 0.24 & 225 & 12 & 5.2 \\
\hline S. S. & 26 & 0.12 & 178 & 13 & 6.8 \\
\hline \multicolumn{6}{|l|}{ Patients } \\
\hline L. G. & 105 & 0.24 & 163 & 10 & 5.8 \\
\hline E. P. & 25 & 0.09 & 126 & 20 & 13.7 \\
\hline
\end{tabular}

* Platelets were extracted as described in Methods. The values shown for 5-HT are the amounts of indoles present in the aqueous phase and those for the metabolites 5-HIAA and 5-hydroxytryptophol (Tpol) are the amounts in the organic phase after extraction of the acidic supernate with ethyl acetate. TLC on the organic phase was also performed for patient L. G. and control D. Y. that their platelets might contain more metabolites than normal subjects. To examine this possibility, we extracted the platelets of patients L. G. and E. P and two normal subjects, starting with the amount of PRP indicated in Table II, by the procedure outlined in Methods. By TLC, no metabolites were detectable (by fluorescence) in either patient L. G. or control D. Y. Since 2-3 nmol of either metabolite could have been detected by this method, the findings indicated that neither was present in an amount greater than $10 \%$ of the total hydroxyindoles in the platelets of these two subjects. Actual measurement of the hydroxyindole content in the extracts indicated that the total content of metabolites (5-HIAA + 5-hydroxytryptophol) in the two normal subjects and in patient L. G. was $5-7 \%$ of the total platelet hydroxyindoles. In patient E. P., however, the percentage of metabolites was $14 \%$. (This patient also metabolized $\left[{ }^{3} \mathrm{H}\right] 5-\mathrm{HT}$ more extensively than patient E. G.; see Table I). These studies were not done in patient S. M.

\section{DISCUSSION}

The diagnostic features of storage pool disease are the markedly diminished content of platelet ADP and the relatively lesser diminution of ATP, resulting in an increased ATP/ADP ratio (Fig. 1). As discussed in detail previously $(22,47)$, these findings are due to the deficiency of a special, nonmetabolic pool of adenine nucleotides (the storage pool) that in normal platelets 
has a particularly high content of ADP. We found a decreased content of platelet 5-HT in all seven patients with storage pool disease studied, and the levels showed a good correlation with those obtained for ATP. The latter finding is consistent with previous suggestions that 5-HT and ATP in platelets are complexed, with bivalent cations, as high molecular-weight aggregates $(18,48,49)$. In contrast to the striking decrease in ADP obtained in all patients, the extent to which 5-HT and ATP were decreased was more variable (Fig. 1). The most striking decreases were obtained in the patient S. M. with albinism. Decreased 5-HT (31, 50, 51) and adenine nucleotide (50) values have also been reported in other patients who have both albinism and a bleeding disorder, and the findings in the present study suggest that the platelet defects $(31,50-52)$ in these patients may differ only in degree from those in patients with "idiopathic" storage pool disease.

In addition to the diminished levels of 5-HT and adenine nucleotides, the platelets of patients with storage pool disease and albinism are also deficient in $\mathrm{Ca}^{+2}$ (23) and show diminished numbers of the electron-dense granules $(51,53)$ in which these substances are stored (6-9). As also described in patients with albinism $(31,50)$, their platelets showed an impaired capacity for absorbing radioactive 5-HT, and the type of defect appeared to be similar to that observed in normal platelets treated with reserpine, a drug that specifically blocks the incorporation of $5-\mathrm{HT}$ into the platelet granules $(40-42)$. These findings suggest that the basic defect in storage pool disease may be either a decreased number of the dense granules or a functional defect in their storage capacities. An impaired capacity of the dense granules for storing 5-HT would appear to provide the most satisfactory explanation for the diminished 5-HT content of their platelets.

The findings in the present study further suggest that the platelet 5-HT in patients with storage pool disease (and the albinism variant of this disorder) may be metabolized more rapidly than that in normal platelets. For example, incubation of PRP from patients E. P., L. G., and S. M. with $\left[{ }^{3} \mathrm{H}\right] 5-\mathrm{HT}$ for $5 \mathrm{~h}$ resulted in the appearance of more $\left[{ }^{3} \mathrm{H}\right] 5$-HIAA (S. M. $\gg$ E. P. $>$ L. G.), particularly in the plasma, than in similar studies performed with the PRP of normal subjects. Using somewhat different experimental conditions, Hardisty, Mills, and Ketsa-Ard also found an increased amount of an unidentified radioactive metabolite of 5-HT after incubating a suspension of washed platelets obtained from their albino patient for $1 \mathrm{~h}$ with $\left[{ }^{14} \mathrm{C}\right] 5-\mathrm{HT}$ (50). It is not clear why increased amounts of radioactive metabolites of 5-HT were not found in the three members of family $\mathrm{C}$ who were studied. Other differences between the platelet defects in this family and those in other, unrelated patients with storage pool disease have been previously noted $(26,27)$. In addition to an increased metabolism of $\left[{ }^{3} \mathrm{H}\right] 5-\mathrm{HT}$, we also found increased amounts of endogenous 5-HT metabolites in the platelets of patient E. P. (S. M. was not studied in this regard). Future studies to detect a possible increase in the urinary excretion of 5-HT metabolites in patients with storage pool disease are anticipated. The increased capacity for metabolizing platelet $5-\mathrm{HT}$ in storage pool disease is best explained at present by the diminished capacity of their platelets for accumulating and sequestering 5-HT in storage granules. As a result of this latter defect, a relatively larger percentage of the 5-HT transported through the plasma membrane may remain unprotected from monoamine oxidase present on mitochondrial membranes.

The impaired release of platelet-bound $\left[{ }^{14} \mathrm{C}\right] 5-\mathrm{HT}$ by collagen that we found in storage pool disease could be due to a relatively smaller percentage of the absorbed 5-HT entering the storage granules, if the latter are the source of the 5-HT extruded from the cell during the release reaction (54). However, in previous studies we found that the release of heparin-neutralizing activity (platelet factor $4, \mathrm{PF}_{-4}$ ) by collagen or epinephrine was also impaired in storage pool disease (28), although the total content of PF-4 in their platelets was normal, and Hardisty et al. reported that the thrombin-induced release of acid hydrolases was decreased in the albinism variant of this syndrome (50). In addition, synthesis of prostaglandins $E_{2}$ and $F_{2 \alpha}$, which is closely associated with the release reaction (55), is also impaired in storage pool disease (56). These findings suggest that the release mechanism may be defective in this disorder, and this would explain the impaired release of platelet-bound $\left[{ }^{14} \mathrm{C}\right] 5-\mathrm{HT}$ that we found.

We confirmed the observations of Baumgartner and Born that the aggregation of platelets by $5-\mathrm{HT}$ is inhibited by their prior incubation with 5-HT (15-17). These authors suggested that during the preincubation period, 5-HT is transported through the membrane by receptors from which the amine then dissociates and is taken up in the storage granules. With increasing concentrations of 5-HT (see Fig. 2) or where the storage capacity of the platelet granules is inhibited by reserpine $(16,17)$, the receptors become increasingly saturated with 5-HT and, hence, are unable to react with the second dose of this amine. Therefore, 5-HT-induced aggregation is inhibited, and this effect was more pronounced in patients with storage pool disease. The latter finding is consistent both with the previous conclusions that the platelets of these patients have a limited capacity for storing 5-HT and with the hypothesis of Baumgartner and Born that the aggregation of platelets by $5-\mathrm{HT}$ is mediated by the same receptors on the 
plasma membrane that are involved in its uptake (1517).

As the role of $5-\mathrm{HT}$ in hemostasis is not clear at present, the clinical significance of the abnormalities in 5-HT content, metabolism, release, and aggregation that we found in patients with storage pool disease remains to be determined. Recently, a type of platelet defect similar to that in storage pool disease has been described in an inbred strain of rat (57). As in storage pool disease, the platelets of these rats (the fawnhooded strain) are deficient in both adenine nucleotides and 5-HT (57). In addition, the behavior of these rats appears to be markedly different than that of other strains of this animal, ${ }^{2}$ and significant behavioral differences, evaluated by a variety of tests, have recently been documented. ${ }^{3}$ Since some, but by no means all, of the patients with storage pool disease have had psychiatric problems of varying severity, it is entirely possible that biochemical abnormalities involving 5-HT in platelets may sometimes reflect abnormalities of a more general nature in both man (58-60) and experimental animals.

\section{ACKNOWLEDGMENTS}

This work was supported in part by U. S. Public Health Service Grant HL 14595 from the National Heart and Lung Institute.

\section{REFERENCES}

1. Rand, M., and G. Reid. 1951. Source of 'serotonin' in serum. Nature (Lond.). 168:385.

2. Garattini, S., and L. Valzelli. 1965. Serotonin. Elsevier, N. V. Uitgevers Mig., Amsterdam. 53-58.

3. Hardisty, R. M., and R. S. Stacey. 1957. Platelet 5hydroxytryptamine (HT) in disorders of the blood. Br. J. Haematol. 3 : 292-298.

4. Born, G. V. R., and R. E. Gillson. 1959. Studies on the uptake of 5-hydroxytryptamine by blood platelets. J. Physiol. (Lond.). 146: 472-491.

5. Michal, F. 1969. D-receptor for serotonin on blood platelets. Nature (Lond.). 221: 1253-1254.

6. Tranzer, J. P., M. Da Prada, and A. Pletscher. 1966. Ultrastructural localization of 5-hydroxytryptamine in blood platelets. Nature (Lond.). 212: 1574-1575.

7. Da Prada, M., A. Pletscher, J. P. Tranzer, and H. Knuchel. 1967. Subcellular localization of 5-hydroxytryptamine and histamine in blood platelets. Nature (Lond.). 216: 1315-1317.

8. Davis, R. B., and J. G. White. 1968. Localization of 5-hydroxytryptamine in blood platelets: an autoradiographic and ultrastructural study. Br. J. Haematol. 15: 93-99.

9. White, J. G. 1969. Dense bodies of human platelets: inherent electron opacity of serotonin storage particles. Blood J. Hematol. 33 : 598-606.

10. Pletscher, A. 1968. Metabolism, transfer and storage of 5-hydroxytryptamine in blood platelets. Br. J. Pharmacol. Chemother. 32: 1-16.

${ }^{2}$ T. B. Tschopp. Personal observations.

${ }^{3}$ E. Tobach. Personal communications.
11. Paasonen, M. K., and M. M. Airaksinen. 1965. Metabolism of 5-hydroxytryptamine in blood platelets of rabbit. Ann. Med. Exp. Biol. Fenn. 43: 236-240.

12. Bartholini, G., A. Pletscher, and H. Bruderer. 1964. Formation of 5-hydroxytryptophol from endogenous 5hydroxytryptamine by isolated blood platelets. Nature (Lond.). 203: 1281-1283.

13. Da Prada, M., G. Bartholini, and A. Pletscher. 1965 Effect of monoamine liberators on the metabolism of 5-hydroxytryptamine in platelets. Biochem. Pharmacol. 14: 1721-1726.

14. Mitchell, J. R. A., and A. A. Sharp. 1964. Platelet clumping in vitro. Br. J. Haematol. 10: 78-93.

15. Baumgartner, R., and G. V. R. Born. 1968. Effects of 5-hydroxytryptamine on platelet aggregation. Nature (Lond.). 218: 137-141.

16. Baumgartner, H. R. 1969. 5-hydroxytryptamine uptake and release in relation to aggregation of rabbit platelets. J. Phy'siol. (Lond.). 201 : 409-423.

17. Baumgartner, H. R. 1970. Effects of 5-hydroxytryptamine on platelet aggregation. Thromb. Diath. Haemorrh. Suppl. 42: 21-35.

18. Pletscher, A., M. Da Prada, K. H. Berneis, and J. P. Tranzer. 1971. New aspects on the storage of 5-hydroxytryptamine in blood platelets. Experientia (Basel). 27: 993-1002.

19. Holmsen, H., and H. J. Day. 1971. Adenine nucleotides and platelet function. Ser. Hacmatol. 4 : 28-58.

20. Holmsen, H., H. J. Day, and E. Storm. 1969. Adenine nucleotide metabolism of blood platelets. VI. Subcellular localization of nucleotide pools with different functions in the platelet release reaction. Biochem. Biophys. Acta. $186: 254-266$.

21. Holmsen, H., and H. J. Weiss. 1970. Hereditary defect in the platelet release reaction caused by a deficiency in the storage pool of platelet adenine nucleotides. $\mathrm{Br}$. J. Haematol. 19: 643-649.

22. Holmsen, H., and H. J. Weiss. 1972. Further evidence for a deficient storage pool of adenine nucleotides on platelets from some patients with thrombocytopathia"storage pool disease." Blood J. Hematol. 39: 197-209.

23. Day, H. J., H. Holmsen, M. C. Scrutton, and H. J. Weiss. 1973. Metal content of platelets obtained from patients with storage pool deficiency. Abstracts 4th International Congress on Thrombosis and Hemostasis, G. Gistel, Vienna. 262.

24. Weiss, H. J. 1967. Platelet aggregation, adhesion and adenosine diphosphate release in thrombopathia (platelet factor-3 deficiency) - a comparison with Glanzmann's thrombasthenia and von Willebrand's disease. Am. J. Med. 43: 570-578.

25. Weiss, H. J., P. A. Chervenick, R. Zalusky, and A. Factor. 1969. A familial defect in platelet function associated with impaired release of adenosine diphosphate. N. Engl. J. Med. 281: 1264-1270.

26. Weiss, H. J., and J. Rogers. 1972. Thrombocytopathia due to abnormalities in the platelet release reactionstudies on six unrelated patients. Blood J. Hematol. 39: 187-196.

27. Weiss, H. J. 1972. Abnormalities in platelet function due to defects in the release reaction. Ann. N. Y. Acad. Sci. 201: 161-173.

28. Weiss, H. J., and J. Rogers. 1973. Platelet factor 4 in platelet disorders. Storage location and the tequirement of endogenous ADP for its release. Proc. Soc. Exp. Biol. Med. 142: 30-35. 
29. Safrit, H., H. J. Weiss, and G. Phillips. 1972. Platelet phospholipids and fatty acids in patients with primary defects of platelet function. Lipids. $7: 60-67$.

30. Fitzpatrick, T. B., and W. C. Quevedo, Jr. 1966. Albinism. Metab. Basis Inherited Dis. 3: 326-340.

31. Maurer, H. M., J. A. Wolff, S. Buckingham, and A. R. Spielvogel. 1972. "Impotent" platelets in albinos with prolonged bleeding times. Blood J. Hematol. 39: 490499.

32. Holmsen, H., E. Storm, and H. J. Day. 1972. Determination of ATP and ADP in blood platelets: a modification of the firefly luciferase assay for plasma. Anal. Biochem. 46: 489-501.

33. Crosti, P. F., and P. E. Luchelli. 1962. An easy method to determine the serotonin content of human platelets. J. Clin. Pathol. 15 : 191-193.

34. Contractor, S. F. 1964. The estimation of 5-hydroxytryptamine in human platelets. Biochem. Pharmacol. 13: 1351-1357.

35. Holmsen, H., A. C. Østvold, and H. J. Day. 1973. Behaviour of endogenous and newly absorbed serotonin in the platelet release reaction. Biochem. Pharmacol. 22 : 2599-2608.

36. Weiss, H. J., L. M. Aledort, and S. Kochwa. 1968. The effect of salicylates on the hemostatic properties of platelets in man. J. Clin. Invest. 47: 2169-2180.

37. Klein, D. C., and A. Notides. 1969. Thin-layer chromatographic separation of pineal gland derivatives of serotonin $-{ }^{14}$ C. Anal. Biochem. 31: 480-483.

38. Smith, I., L. J. Rider, and R. P. Lerner. 1967. Chromatography of amino acids, indoles and imidazoles on thin layers of Avicel and cellulose and on paper. J. Chromatogr. 26 : 449-455.

39. Snedecor, G. W., and W. G. Cochran. 1967. Statistical Methods. Iowa State University Press, Ames, Iowa. 3265 and 135-171.

40. Da Prada, M., and A. Pletscher. 1968. Isolated 5-hydroxytryptamine organelles of rabbit blood platelets: physiological properties and drug-induced changes. $B r$. J. Pharmacol. 34 : 591-597.

41. Da Prada, M., A. Pletscher, J. P. Tranzer, and $\mathrm{H}$. Knuchel. 1968. Action of reserpine on subcellular 5-hydroxytryptamine organelles of blood platelets. Life Sci. 7: 477-480.

42. Da Prada, M., and A. Pletscher. 1969. Different localization of reserpine and tyramine within the 5-hydroxytryptamine organelles of blood platelets. Experientia (Basel). 25: 923-924.

43. Pletscher, A., and J. P. Tranzer. 1967. Action of reserpine and imipramine on intracellular storage of 5hydroxytryptamine in blood platelets. Experientia (Basel). 23: 289-291.

44. Zucker, M. B., and J. Peterson. 1968. Inhibition of adenosine diphosphate-induced secondary aggregation and other platelet functions by acetylsalicylic acid ingestion. Proc. Soc. Exp. Biol. Med. 127: 547-551.

45. Zeller, E. A., B. H. Babu, and G. J. Stanich. 1969. On the occurrence and measurement of monoamine oxidase activity in human blood platelets and plasma. Blood $\mathrm{J}$. Hematol. 34 : 527-528.

46. Paasonen, M. K., and E. Solatunturi. 1965. Monoamine oxidase in mammalian blood platelets. Ann. Med. Exp. Biol. Fenn. 43 : 98-100.

47. Holmsen, H. 1973. Compartmentation of adenine nucleotides in platelets. In Erythrocytes, Thrombocytes, Leukocytes. Recent Advances in Membrane and Metabolic Research. E. Gerlach, K. Moser, E. Deutsch, and W. Wilmanns, editors. Georg Thieme Verlag KG, Stuttgart, Germany. 321-327.

48. Da Prada, M., A. Pletscher, and J. P. Tranzer. 1971. Storage of ATP and 5-hydroxytryptamine in blood platelets of guinea-pigs. J. Physiol. (Lond.). 217: 679. 688.

49. Born, G. V. R., G. I. C. Ingram, and R. S. Stacey. 1958. The relationship between 5-hydroxytryptamine and adenosine triphosphate in blood platelets. Br. J. Pharmacol. 13: 62-64.

50. Hardisty, R. M., D. C. B. Mills, and K. Ketsa-Ard. 1972. The platelet defect associated with albinism. Br. J. Haematol. 23 : 697-692.

51. White, J. G., J. R. Edson, S. J. Desnick, and C. J. Witkop. Studies of platelets in a variant of the Hermansky-Pudlak syndrome. Am. J. Pathol. 63: 319-330.

52. Logan, L. J., S. I. Rapaport, and I. Maher, 1971. Albinism and abnormal platelet function. N. Engl. J. Med. 284 : 1340-1345.

53. Weiss, H. J., and R. P. Ames. 1973. Ultrastructural findings in storage pool disease and aspirin-like defects of platelets. Am. J. Pathol. $71: 447-460$.

54. Holmsen, H., H. J. Day, and H. Stormorken. 1969. The blood platelet release reaction. Scand. J. Haematol. Suppl. 8: 3-26.

55. Smith, J. B., C. Ingerman, J. J. Kocsis, and M. J. Silver. 1973. Formation of prostaglandins during the aggregation of human blood platelets. J. Clin. Invest. 52: $965-969$

56. Willis, A. L., and H. J. Weiss. 1973. A congenital defect in prostaglandin production associated with impaired hemostasis in storage pool disease. Prostaglandins. 4 : 783-794.

57. Tschopp, T. B., and M. B. Zucker. 1972. Hereditary defect in platelet function in rats. Blood J. Hematol. 40: 217-226.

58. Siva Sankar, D. V. 1970. Biogenic amine uptake by blood platelets and RBC in childhood schizophrenia. Acta Paedopsychiatr. 37 : 174-182.

59. Jérome, H., and P. Kamoun. 1968. Anomalie de la captation de la sérotonine par les plaquettes sanguines des sujets trisomiques 21. I. Etude des caractéristiques générales de la captation. Bull. Soc. Chim. Biol. 50: 907-921.

60. Bouillin, D. J., and R. A. O'Brien. 1971. Abnormalities of 5-hydroxytryptamine uptake and binding by blood platelets from children with Down's syndrome. $J$. Physiol. (Lond.). 212: 287-297. 